\title{
Flood damage data analysis: towards an improvement of data quality and usability
}

\author{
Daniela Molinari ${ }^{1, a}$, Rafael Prades ${ }^{2}$, Mariano Garcia-Fernandez, Martin Dolan ${ }^{4}$, Scira Menoni ${ }^{5}$, and Daniela Marcellini ${ }^{6}$ \\ ${ }^{1}$ Politecnico di Milano, Department of Civil and Environmental Engineering, Piazza Leonardo da Vinci, 32, Milano, Italy \\ ${ }^{2}$ Direcció General de Protecció Civil, Barcelona, Spain \\ ${ }^{3}$ Agencia Estatal Consejo Superior de Investigaciones Cientificas, Jose Gutierrez Abascal, 2, Madrid, Spain \\ ${ }^{4}$ School of Architecture, Oxford Brookes University, Gipsy Lane, Oxford, UK \\ ${ }^{5}$ Politecnico di Milano, Department of Architecture and Urban Studies, Piazza Leonardo da Vinci, 32, Milano, Italy \\ ${ }^{6}$ Civil Protection Authority - Umbria Region, Via Romana Vecchia, Foligno, Italy
}

\begin{abstract}
The European project IDEA (Improving Damage assessments to Enhance cost-benefit Analyses) is a response to the limited reliability of data currently used to support cost-benefit analyses for natural hazards mitigation; in particular, an improvement of both damage data quality and procedures to collect and manage them is pursued by the project. A comprehensive understanding of (i) how disaster data are presently collected and stored, (ii) main reasons for data collection, (iii) possible uses of collected data, and (iv) stakeholders involved in data collection and management is the first step to improve the present quality, reliability and usability of data. To this aim, several case studies were analysed in the project referring to different hazards, countries and spatial scale. The analysis brought, for each case study, to (i) the characterisation of data owners, data collectors, and data users, and (ii) a critical analysis of damage data in terms of their comprehensiveness in reproducing observed impacts, data sources, formats and level of detail. This paper discusses results obtained for the floods that hit the Umbria Region (Central Italy) in 2012 and 2013, as emblematic of the different case studies analysed in the project. First, the methodological approach followed in the analysis is disclosed. Then, results are presented. Finally, their implication for the project objective are discussed.
\end{abstract}

\section{Introduction}

Reliable estimates of costs and benefits of risk mitigation measures are considered nowadays as crucial for informed decision making and, more specifically, for the development of policies, strategies and measures to prevent or reduce the impact of natural hazards ([1]).

In fact, since their first introduction in the U.S. Flood Control Act of 1936, cost-benefit analysis concepts have been regularly adopted as the base to evaluate the feasibility of flood mitigation proposals by several Countries, for example, the UK, the USA, Australia and the Netherlands ([2,3]). Nonetheless, cost-benefit analysis has been recently introduced as a pillar of Flood Risk Management Plans by the European "Floods Directive" ([4]).

Despite such a long tradition, reliability of costbenefit analysis in the field of flood risk mitigation is still questionable. According to Handmer ([2]), poor quality assessments do not occur because the basic principles and procedures of the analysis are unknown. Rather, a relevant issue regards the low quality of available data used as input for economic analyses, as also stressed by the FP7 CONHAZ project.

In such a context, this paper presents first results from the European project IDEA (Improving Damage assessments to Enhance cost-benefit Analyses). The project aims at responding to the very limited reliability of data currently used to support cost-benefit analyses, by pursuing an improvement of both damage data quality and procedures to collect and manage them. In particular, a set of tools will be developed in the project to enable the (multi-) use of damage data for: damage compensation within the financial arrangements existing in each country, damage forensic investigation to guide recovery toward effective investment and better risk assessments for future events. All the three applications are at the bases of reliable cost-benefit analyses of mitigation measures.

A comprehensive understanding of (i) how disaster data are presently collected and stored, (ii) main reasons for data collection, (iii) possible uses of collected data, and (iv) stakeholders involved in data collection and management, is the first step to improve the present quality, reliability and usability of data collected in the aftermath of floods. To this aim, several case studies were analysed in the project, referring to different hazards, countries and spatial scale (in terms of disaster impacts). The analysis brought, for each case study, to:

- the identification and characterization of data owners, data collectors, and data users;

- a critical analysis of damage data in terms of their comprehensiveness in reproducing observed impacts, data sources (e.g. field survey, acquisition from existing databases), formats (e.g. paper, digital) and level of detail.

This paper discusses results obtained in the analysis of the floods that struck the Umbria Region (Central Italy) in 2012 and 2013, as emblematic of the different case studies analysed in the project. First, the methodological approach followed in the analysis is disclosed. Then, results are presented for the Umbria case studies. Finally, their implication for the project objective are discussed.

\footnotetext{
a Corresponding author: daniela.molinari@polimi.it
} 


\section{Methodological approach}

\subsection{Stakeholders' characterisation}

The methodological approach adopted in the analysis differed among case studies, on the bases of whether (or not) partners in the project either are representing some of the stakeholders or have direct contacts with them. This is the case of the Italian case studies described in this paper that involve the Umbria Regional Civil Protection Authority (RCPA) as a project partner; the authority is on the frontline of data collection and management both in the emergency and the recovery phase (see Section 3.2.2).

In such a context, stakeholders were first identified thanks to the experienced gained on the field by project partners. Then, tailored meetings were organised in order to infer knowledge on:

- stakeholders roles, responsibilities, needs, requirements and constraints as data users, owners, or collectors;

the procedures they presently adopt for data collection, storage and analysis, their advantages and weaknesses with respect to both required resources and usefulness in reproducing a comprehensive picture of disaster impacts.

Information gathered during the meetings was then integrated with information collected by an "ad-hoc" developed questionnaire that was sent to individual stakeholders in a second time, and by information acquired from the analysis of laws and regulations on flood risk management.

Whereby interested parties are not involved in the project, a different path was followed. A review of event reports and the literature allowed first to identify principle stakeholders. Then the questionnaire was sent to individual stakeholders so that profiles were created for each of them based on questionnaires results. Preliminary information was further integrated with knowledge acquired by direct interviews arranged with engaged stakeholders. Interestingly, further stakeholders were identified through such discussions.

\subsubsection{Stakeholders in data collection, storage and analysis}

As regard data owners, stakeholders' characterisation implied the identification of (i) which data they are responsible for, (ii) at which spatial and temporal scales, (iii) with what rights (e.g. private or public owners, voluntarily or by law, etc.) and (iv) tools used for the storage of data. With respect to data collectors, investigation concerned (i) reasons for data collection, (ii) type of collected data, (iii) spatial and temporal scales of interest, (iv) tools and procedures presently implemented, and (v) available human and economic resources. Data users were characterised in terms of (i) data of interest, (ii) scales of interest and (iii) uses of data (Table 1).

Moreover, links among the different stakeholders were identified whereas owning, collection and use can be in charge of one or more subjects, even for the same "category" of loss (e.g. damage to residential or industrial sectors, agriculture, etc.). Likewise, links exist because data are shared among the different stakeholders for the different purposes related to risk management.

\subsubsection{Existing practices}

Existing practices were analysed during the stakeholders characterisation as far as tools and procedures presently adopted for data collection, tools used for the storage of data and available human and economic resources are concerned (see Section 3.3).

\subsection{Data analysis}

As regard data analysis, the first step was the identification of data sources (i.e. owners), starting from information obtained during meetings and interviews with stakeholders. Then data were physically collected and stored. A subsequent analysis of the comprehensiveness of data was performed. In detail, availability of data to depict the full range of likely impacts as well as their drivers (i.e. hazard, exposure and vulnerability factors) was assessed. At last, an analysis was performed on main data sources, format and level of detail (see Table 2).

\section{Analysis of the Umbria floods in 2012 and 2013}

\subsection{Description of the case studies area}

The Umbria region is located in central Italy (Figure 1) and covers $8456 \mathrm{~km} 2$ with a population of 883000 inhabitants. Most of its territory is made of the Apennines Mountains and hillside. Available historic data highlight the hazardousness of the area, characterized by a variety of phenomena, including debris flow, flash floods, riverine floods in reclaimed land and suspended levees. In the last century more than 100 of these events occurred, with peaks in the winter time in the months of November and February. The Tiber River, which flows from North to South for almost $100 \mathrm{~km}$, provoked several inundations, but significant damage has also been caused by its tributaries and by minor channels and creeks. The overall economic impact, to both private and public assets, amount to $1 \mathrm{MD}$ Euros damage for the last 10 years only. In this paper, impacts caused by the two floods that occurred in November 2012 and 2013 in the region are analysed. The case studies are significant for the project as they affected a large portion of the region (58 and 43 out of 92 municipalities respectively), implying damage to several exposed sectors and the active involvement of a variety of stakeholders in the aftermath of floods, at different spatial and administrative level. 


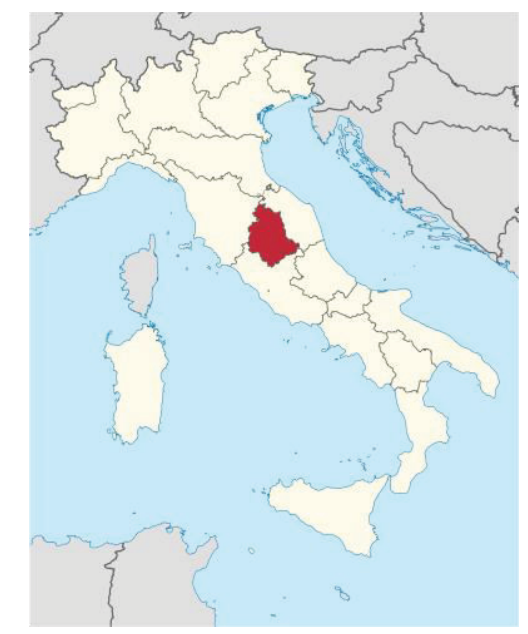

Figure 1. Location of Umbria region (source: Wikimedia Commons - TUBS)

\subsection{Results of stakeholders' characterisation}

Table 1 shows the results of stakeholders' characterisation (as data owners, collectors and users respectively) with respect to the stakeholder "Municipal Authorities". Similar tables are available for all the other identified stakeholders in the case studies (being: Province Authorities, Region Authority - that includes RCPA, National Civil Protection Authority, Mountain Authorities, Private Citizens, Utilities companies, Insurance companies and Trade associations) and, more in general, for all those identified in the other case studies analysed in the project ([5]).

The analysis highlights that the Italian context presents a mix of private and public stakeholders.

\subsection{Private stakeholders}

Private subjects mainly consist of companies managing private services like electricity, telecommunication, gas, water and sewage, railways and national roads (i.e. utility companies in the following); moreover, trade associations, citizens and insurance companies may be included among private stakeholders.

The analysis reveals first that similarities exist among utilities companies. As data owners, they typically possess information on the location and vulnerability of exposed assets (as far as their respective service is concerned), and information on flood hazard in terms of potentially flooded areas. The location of high vulnerable items which could be severely affected by service disruption is also usually known like, for example, the location of hospitals with respect to electric lines. Such information, as well as data on flood hazard, is acquired from the Region Authority or by open-data.

As far as data collection is concerned, utilities companies typically gather data on the extension of the flooded area and on direct and indirect damage (i.e. service disruption) to their network, after every flood event. The disruption of interconnected services and systems is also of interest and is usually acquired from the RCPA.

Finally, as regard data users, elaborations performed by utilities companies mainly consist in tables, statistics and maps to support both the emergency and the recovery phase and, when applicable, compensation requests to national and/or private funds.

Utilities companies own and collect data voluntary for the objective of managing the service and the network. They do not share data with other subjects/authorities apart from information on service interruption that must be communicated by law to the RCPA to allow for an appropriate management of the emergency phase. Interestingly, information on the location (and then on the vulnerability) of most of service networks is unknown also by the RCPA, with significant repercussions on flood risk management effectiveness.

Data collection is usually performed by utilities companies at the individual level (i.e. single item in the network) whereby data elaboration can be performed both at the individual or aggregated level, depending on the objective of the analysis. For example, the spatial distribution of service interruption must be known at the regional level in order to plan the more appropriate strategy of intervention (e.g. where power units must be deployed). Compensation requests or recovery strategies require instead analyses at the individual level.

Utilities companies collect and elaborate data few hours after the floods, as far as emergency issues are concerned, and some days/months after the event for recovery and compensation purposes.

Citizens collect and possess information on damage suffered by own private properties (i.e. residences and industrial/commercial activities). They may also collect information on the hazard at the micro-scale (e.g. water depth, presence of sediments, contaminants, water velocity, etc., at building location) which may be useful to risk analysts to infer knowledge on the hazard scenarios and to improve hazard models; however, such information is hardly communicated to other stakeholders. Citizens do not have any obligations to collect data but they have to do it in order to access national funds.

Trade associations act as a bridge between business owners and the authority responsible for damage compensation, i.e. the Region Authority.

In the case of flood, they acquire data collected by private citizens (on direct and indirect damaged suffered by their business), elaborate them in order to get a synthesising figure, and finally transmit the data to the Region Authority. Data are usually acquired and elaborated some days/months after the floods in order to report both direct and indirect damages.

Besides damage data, trade associations typically own information on the location and vulnerability of industrial and commercial activities. 


\subsection{Public stakeholders}

At the regional level, public stakeholders can be divided into two categories. Those which are responsible of a specific exposed sector (like Provincial Authorities for roads, Agriculture Regional Service, etc.), and those which have duties on all public exposed sectors (like Municipal Authorities and Region). Then the National Civil Protection Department is included among public subjects.

The first category of stakeholders (i.e. sector specific) presents some similarities with utilities companies. They typically own information on flood hazard, exposure and vulnerability of exposed assets (for their specific sector) and collect data regarding direct and indirect damage to items within their competency. Elaborations performed mainly consist in tables, statistics and maps to support the emergency and the recovery phase, the revision of flood risk management strategies and compensation requests to national funds.

Contrary to private companies, public stakeholders must share collected and elaborated data by law, with both the RCPA during the emergency (i.e. this is typically the case of information on roads disruption), and with the Region Authority to ask for compensation. Moreover, data must be supplied to any public subject, under request. Data on location and vulnerability of exposed items is also shared with the Region Authority, in time of peace. Like private companies, data collection is usually performed at the individual level, whereby data elaboration can be performed both at the individual or regional level. Data are usually collected and elaborated few hours after the floods as far as emergency issues are concerned and some days/months after the event for recovery and compensation purposes.

Municipal Authorities and the Region Authority are the most "active stakeholders", because they have duties and responsibilities on different public exposed sectors both in time of peace and during the emergency (respectively at the municipality and regional level). By law, in time of peace, they own and share all available information on the different exposed sectors (location, vulnerability, etc.) as well as on flood hazard. Similarly, after the event, they must acquire damage data to all sectors within their competency and elaborate them (in terms of maps, tables, statistical analyses, reports) for both the emergency, the recovery and the compensation phase. The Region Authority also use collected data to improve risk mitigation strategies.

Municipalities are usually interested in collecting and elaborating data at the individual level, while the Region Authority mostly analyses aggregated data at the municipal or regional level. Indeed, the Region Authority is the subject responsible by law to collect, manage and elaborate all the data coming from the other stakeholders both to face the emergency (i.e. through the RCPA) and for the compensation phase. Collected data are then sent to the National Civil Protection Department that decides on reimbursements.

Temporal scales of interest span from few hours/days after the flood (to collect and elaborate direct damage for the emergency phase) to some days/months after the flood (to collect and elaborate direct/indirect damage for the recovery, compensation phase and for the improvements of risk mitigation strategies).

Municipalities also act as a bridge between private citizens and the Region Authority, gathering and transmitting data collected by citizens on damage to residential buildings, in order to ask for compensation.

\subsection{Results on existing practices for data collection}

Existing practices, tools and resources currently implemented by each stakeholder are also reported in Table 1 (and similar ones). As before, a distinction can be done between private and public subjects.

Starting from private stakeholders (i.e. utilities companies in detail), data are directly gathered on the field, by survey or by means of sensors deployed along the network. Otherwise, damage data are acquired indirectly, from users/clients that communicate requests for intervention, usually by means of a call centre. Data are collected by qualified personnel and are stored in proprietary databases that may also have GIS functionalities.

Private citizens collect data according to forms implemented by the Region Authority for compensation requests. Filled-in form are delivered to municipalities or trade associations in paper form or as a scan copy of paper documents.

Public authorities collect data on the field as far as items within their competency are concerned. Otherwise, they acquire information from other public authorities, the RCPA or utility companies, depending on the sector under consideration. There are not specific procedures to carry out field survey nor for data acquisition. Data are stored into GIS or commercial databases with no standards/shared protocols among the different authorities. Moreover, data are often stored in paper form or scan copies of paper documents. Data are collected by the authorities' personnel with the economic resources available to deal with the flood. A general lack of both economic and human resources is observed.

The Region Authority gathers data on the field by sensors, satellites, photos and so on as far as the hazard is concerned (e.g. extension of the flooded areas, discharge, etc.). Damage data are instead acquired from public authorities and trade associations. During the emergency information is transmitted by fax/telephone, with no specific standards. Within the objective of damage compensation, pre-defined forms are instead implemented. Such forms are often sent to the Region Authority in paper form or scan copies of paper documents. Data are stored into GIS or commercial databases. 


\begin{tabular}{|c|c|c|}
\hline \multicolumn{2}{|c|}{ Stakeholder } & MUNICIPAL AUTHORITIES \\
\hline \multicolumn{2}{|c|}{ Type } & PUBLIC \\
\hline \multicolumn{3}{|r|}{ DATA OWNER } \\
\hline \multirow{7}{*}{ 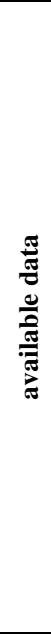 } & Type of data & exposure, vulnerability, hazard direct damage (physical \& monetary), indirect damage, mitigation actions \\
\hline & $\begin{array}{l}\text { sectors } \\
\text { (type of data) }\end{array}$ & $\begin{array}{l}\text { base maps (administrative boundaries), physical event (rivers track, hazard zones, affected areas, induced landslides), } \\
\text { protective measures within their competency (location/vulnerability, physical \& monetary direct damage, indirect damage, } \\
\text { mitigation actions), people (exposed people, death, injured, affected, evacuees, mitigation actions), roads within their } \\
\text { competency (location/vulnerability, physical \& monetary direct damage, indirect damage, mitigation actions), railways } \\
\text { (location/vulnerability, indirect damage), electric lines (indirect damage), gas lines (indirect damage), telecommunication lines } \\
\text { (indirect damage), water and sewage within their competency (location/vulnerability, physical \& monetary direct damage, } \\
\text { indirect damage, mitigation actions), strategic/public buildings within their competency (location/vulnerability, physical and } \\
\text { monetary direct damage, indirect damage, mitigation actions), commercial and industrial premises (location/vulnerability, } \\
\text { physical and monetary direct damage), residential buildings (location/vulnerability, physical and monetary direct damage), } \\
\text { cultural heritage within their competency (location/vulnerability, physical direct damage, indirect damage, mitigation actions), } \\
\text { emergency management (employed resources, emergency costs, personnel), documents (ordinances, emergency plans, master } \\
\text { plans) }\end{array}$ \\
\hline & spatial scale & single items, municipality \\
\hline & temporal scale & Before the event, observed data after the event \\
\hline & right & by law \\
\hline & tools & own database, paper form \\
\hline & links & municipalities, regional, and other local authorities should share the same base data/exposure data \\
\hline \multicolumn{3}{|r|}{ DATA COLLECTOR } \\
\hline \multirow{10}{*}{ 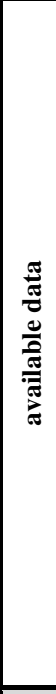 } & Type of data & hazard, direct damage, indirect damage, mitigation actions \\
\hline & $\begin{array}{l}\text { sectors } \\
\text { (type of data) }\end{array}$ & $\begin{array}{l}\text { physical event ( affected areas, induced landslides), protective measures within their competency (physical direct damage, } \\
\text { indirect damage, mitigation actions), people (death, injured, affected, evacuees, mitigation actions), roads within their } \\
\text { competency (physical direct damage, indirect damage, mitigation actions), railways (indirect damage), electric lines (indirect } \\
\text { damage), gas lines (indirect damage), telecommunication lines (indirect damage), water and sewage within their competency } \\
\text { (physical direct damage, indirect damage, mitigation actions), strategic/public buildings within their competency (physical } \\
\text { direct damage, indirect damage, mitigation actions), commercial and industrial premises (physical \& monetary direct damage) } \\
\text { residential buildings (physical \& monetary direct damage), cultural heritage within their competency (physical direct damage, } \\
\text { indirect damage, mitigation actions) }\end{array}$ \\
\hline & spatial scale & single items, municipality \\
\hline & temporal scale & soon after the event, months after the event (for residences, mitigation actions, indirect damage) \\
\hline & right & by law \\
\hline & reasons & loss accounting (for recover and victims compensation), revision of pre-existing risk assessment and emergency plans \\
\hline & procedure & $\begin{array}{l}\text { field survey (physical event, public infrastructures and public items), acquisition from private citizens (residences), acquisition } \\
\text { from utilities companies (private infrastructures), acquisition from other local authorities (for protective measures, provincial } \\
\text { roads) }\end{array}$ \\
\hline & tools & Information not available \\
\hline & resources & technical staff, volunteers \\
\hline & links & gathering of data from utility companies (private infrastructures), Mountain Authority (protective measures), Province (roads) \\
\hline \multicolumn{3}{|r|}{ DATA USER } \\
\hline \multirow{8}{*}{ : } & Type of data & affected areas, monetary damage \\
\hline & $\begin{array}{l}\text { Sectors } \\
\text { (type of data) }\end{array}$ & $\begin{array}{l}\text { physical event (affected areas, induced landslides), protective measures within their competency (physical direct damage, } \\
\text { mitigation actions), people (evacuees, mitigation actions), roads within their competency (physical direct damage, mitigation } \\
\text { actions), water and sewage within their competency (physical direct damage, mitigation actions), strategic/public buildings } \\
\text { within their competency (physical direct damage, mitigation actions), commercial and industrial premises (physical \& } \\
\text { monetary direct damage), residential buildings (physical \& monetary direct damage), cultural heritage within their competency } \\
\text { (physical direct damage, mitigation actions, emergency management (employed resources, emergency costs, personnel) }\end{array}$ \\
\hline & spatial scale & single items, municipality \\
\hline & temporal scale & observed data after the event \\
\hline & right & by law (declaration of state of emergency) \\
\hline & reasons & emergency management, recovery and compensation \\
\hline & elaboration & tables, reports, maps, statistical analysis \\
\hline & links & $\begin{array}{l}\text { transmission of data to Regional Civil Protection Authority (during emergency), Regional Authority (for compensation), } \\
\text { Province and Prefecture }\end{array}$ \\
\hline
\end{tabular}

Table 1. Characterisation of Municipal Authorities as data owners, collectors and users. 


\subsection{Database of available data}

Table 2 shows available data for the 2012 flood. A similar table is available for the 2013 flood and, more in general, for all case studies analysed in the project ([5]).

In the table, data of interest are organised according to exposed sectors. An indication is supplied on whether or not the datum is available for the case study and on the data source.

The resulting scenario highlights a good coverage of data, for both the case studies. Data related to the location and vulnerability of exposed elements are available for most of sectors and mainly derive from regional databases. An exception is represented by the electricity and the telecommunication infrastructures. The latter are managed by private utilities companies that usually do not share information with external parties (see section 3.2.1); as a consequence, no data were found to characterise them.

For the same reason, direct and indirect damage to private infrastructures is partly known. In general, available data regard direct damage (in physical units) and service disruption; that is the information utilities companies must communicate by law to the RCPA (see section 3.2.1).

Monetary damages are mostly unknown for infrastructures, apart when private companies request access to national funds (like in the case of the water and sewage companies during the 2012 flood).

As far as public sectors are concerned, both the physical and the monetary damage are generally known because the Region Authority collect such information to deal with the compensation phase (see section 3.2.2).

An exception is represented however by the Agriculture sector. The latter is managed by a specific Regional Service with procedures for data collection and compensation different than those of the other sectors. Access to data on agriculture revealed then to be difficult mainly because of a lack of coordination and information exchange among the Regional Service and the Region Authority.

Available information on private buildings (i.e. residences and industrial/commercial premises) usually regards their location and the monetary value of reported damages, as far as buildings' owners ask for compensation. The knowledge of buildings vulnerability and of physical damage is available instead only for a set of buildings that were individually surveyed after the two floods, during a pilot survey (see Section 4).

As regard spatial scales, available data can refer to aggregated units (like emergency costs borne by a municipality), to the individual level (e.g. monetary damage to a specific roads) or to the component level (e.g. physical damage to windows and doors), depending on the sector under investigation.

Available data can have different digital files extensions. Most common are .shp, .xls, .doc, .pdf.

\section{Analysis of results: criticalities for the development of the project}

The main criticalities revealed by the analysis of the Italian case studies derive from the present situation where several stakeholders act without a coordination, shared protocols and procedures and without a common goal. This lead to several problems in terms of data quality and usability, as well as in terms of resources optimization:

- the same information may be owned/used by different stakeholders (e.g. the roads map); however, incoherence was observed in some cases among data owned by the different stakeholders. For example, certain roads are reported on a map but not on another one, roads classification changes from one map to another, and so on. This may be due to both the use of different data sources (e.g. open data vs. regional data), or to modifications of original data made by the users. Incoherence limits the possibility of comprehensive/effective risk mitigation strategies as each stakeholder defines their strategies on different (and something uncoherent) datasets. A common platform where all stakeholders can share the same data could be useful to overcome present problems and must be developed within the project;

- such a common platform should also avoid problems relating to data sharing, whereby one stakeholder needs to communicate their data to one or more subjects, presently according to different formats and procedures. This implies a waste of time and resources. The platform can function as a place where stakeholders can access data of interest according to users' restrictions. In fact, one of the main obstacle of data sharing is the presence of sensitive data.

- Incoherence is also observed among "the type" of data collected after the two floods. This is due to a lack of standardization in forms/procedures presently adopted to collect data so that they change after every flood. This may lead to several difficulties/impossibility of comparing different events;

- at the same time, also the way in which data are stored are not standardized so that it is possible to find, even for the same event and for the same stakeholder, different databases containing the same information but with a different "structure" (i.e. data fields). This compromises the possibility of defining a comprehensive, unique scenario of occurred impacts. Data standardisation is then a key requirement for the quality and usability of collected data to be implemented in the common platform for data storage and sharing.

- Standardisation must also be achieved in the platform as regards tools currently implemented for data storage, whereas each stakeholders use different GIS or commercial databases to store their data.

- Multi-usability of data is presently not possible. At this time, available data are collected only for emergency management or compensation reasons. Accordingly, important information for damage modelling or damage forensic is presently not available (typically information 
on vulnerability and damage mechanisms). Nonetheless, there is also an issue of scales as data are often collected and shared at aggregated level (i.e. municipal or regional level). This do not allow for a proper investigation of damage mechanisms which is essential for both forensic investigations and damage modelling. Data integration must be envisaged in tools developed by the project, so that all relevant information is collected and stored in the future.

- Private data (and specifically data about utility services) are difficult to obtain because of no legal obligations for private companies to communicate their data to the Region Authority. Private companies must be engaged and convince to share their data by proving the utility of having a common scenario of the flooding event.

- In the case no funds are available for private citizens or when citizens do not ask for compensation, information on damage to residences and industrial/commercial premises is not collected. Data collection procedures must include in the future data gathering also for these sectors to avoid missing key information for cost-benefit analysis of risk mitigation strategies.

With the main objective of overcoming above criticalities, a pilot is presently under test in the Umbria Region consisting in a procedure (i.e. RISPOSTA Reliable InStruments for ex-POST damage Assessment) to be applied every time a flood occurs $([8,9])$. By means of the procedure the Region Authority assumes the role of data coordinator, clearly defining which data must be collected, when, how and by whom after a flood, and how such data must be communicated/shared with the Region Authority. It is the role of the Region Authority then to produce comprehensive event scenarios, on the bases of collected data, which would meet several objectives: from loss accounting and disaster forensic, to the review of risk mitigation strategies.

The procedure is based on specific ICT tools for data collection and management, including a mobile application for data collection on the field and a Web portal (with GIS functionalities) for the management and elaboration of all data. The latter allows users to share their data and organized them according to common procedures (i.e. databases). Moreover, the procedure guarantees coherence of data collected after different events. Presently, the engagement of private utilities in the procedure is partial, as they still not have any kind of obligations to share their data but it is the role of the Region Authority to ask data of interest in case of flood. On the opposite, a full procedure and tools for data collection on private residences and industrial/commercial premises have been developed.

The procedure and associated tools can be used as a starting point to develop tools fostered by the IDEA project.

\section{Analogies and differences with the other case studies}

Findings from the other case studies analysed in IDEA are in line with those discussed in this paper, at least as regard their implications for the development of the project. This means considerations in Section 4 can be generalised also for other institutional contexts and hazards. In particular:

- although stakeholders change from one case study to another (as well as specific sectors for which they are responsible and own/collect/use data), a variety of public and private subjects was identified in every case study that generally act without a coordination and common standards/procedures. This is a problem for data sharing and comparability, and consequently for the quality of available data. The fact that private stakeholders are not obliged to share/communicate their data is another problem for data quality, in terms of comprehensiveness of information.

- data collected in the aftermath of floods do not allow at present the analysis of damage mechanisms, preventing their adoption for forensic investigations and damage modelling (and cost-benefit analyses in their turn).

The importance of a common platform for data sharing as well as of shared procedures for data collection (that envisages also the integration of present missing information) has then identified as a key objective for the IDEA project. 


\begin{tabular}{|c|c|c|c|c|}
\hline \multirow{2}{*}{ Sector } & \multirow{2}{*}{ Data } & \multicolumn{2}{|c|}{ Availability } & \multirow{2}{*}{ Source } \\
\hline & & Yes & No & \\
\hline \multirow{4}{*}{$\begin{array}{l}\text { : } \\
\text { Z् } \\
0 \\
\tilde{D} \\
\tilde{\Xi} \\
\oplus\end{array}$} & DTM & $\mathrm{X}$ & & Army Geographical Centre (IGM) \\
\hline & administrative boundaries & $\mathrm{X}$ & & Region Authority \\
\hline & land use & $\mathrm{X}$ & & Corine Land Cover \\
\hline & census zones & $\mathrm{X}$ & & National statistical Office (ISTAT) \\
\hline \multirow{7}{*}{ 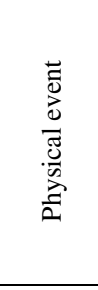 } & hazard zones (from ex-ante hazard assessment) & $\mathrm{X}$ & & Region Authority/National Research Council \\
\hline & river track- for floods & $\mathrm{X}$ & & Region Authority \\
\hline & monitoring data (precipitation/water level, etc.) & $\mathrm{X}$ & & Regional Civil Protection (Forecasting Centre) \\
\hline & forecasting data (water level) - for floods & $\mathrm{X}$ & & Regional Civil Protection (Forecasting Centre) \\
\hline & affected areas & $\mathrm{X}$ & & Region Authority/National Research Council/ Municipalities \\
\hline & hazard intensity (water depth, velocity, duration, etc.) & $\mathrm{X}$ & & Survey \\
\hline & induced landslides & $\mathrm{X}$ & & Regional Civil Protection /Municipalities \\
\hline \multirow{6}{*}{ 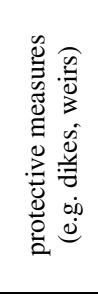 } & location/vulnerability (physical, functional and systemic) & $\mathrm{X}$ & & Regional Environmental Agency (ARPA) \\
\hline & direct damage & $\mathrm{X}$ & & Regional Civil Protection Authority (Logistics section) \\
\hline & direct damage- monetary value & $\mathrm{X}$ & & Regional Civil Protection Authority (Logistics section) \\
\hline & indirect damage (e.g. disruption, systemic) & & $\mathrm{X}$ & \\
\hline & $\begin{array}{l}\text { indirect damage (e.g. disruption, systemic) - monetary } \\
\text { value }\end{array}$ & & $\mathrm{X}$ & \\
\hline & mitigation actions (before and during the event) & $\mathrm{X}$ & & $\begin{array}{l}\text { Regional Civil Protection (Logistics section)/Mountain } \\
\text { Authorities }\end{array}$ \\
\hline \multirow{7}{*}{$\frac{0}{2}$} & exposed people (e.g. census data) & $\mathrm{X}$ & & Region Authority/National statistical Office (ISTAT) \\
\hline & number of death & $\mathrm{X}$ & & Regional Civil Protection (Emergency Management Centre) \\
\hline & number of injured & $\mathrm{X}$ & & Regional Civil Protection (Emergency Management Centre) \\
\hline & number of affected people & $\mathrm{X}$ & & Regional Civil Protection (Emergency Management Centre) \\
\hline & number of evacuee & $\mathrm{X}$ & & Regional Civil Protection (Emergency Management Centre) \\
\hline & intangible damage & & $\mathrm{X}$ & \\
\hline & mitigation actions (before and during the event) & & $\mathrm{X}$ & \\
\hline \multirow{6}{*}{ 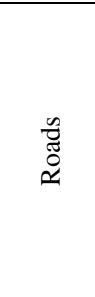 } & $\begin{array}{l}\text { location/vulnerability (e.g. classification, functional and } \\
\text { systemic vulnerability) }\end{array}$ & $\mathrm{X}$ & & Region Authority \\
\hline & direct damage (lines and installation) & $\mathrm{X}$ & & Regional Civil Protection (Logistics section) \\
\hline & direct damage (lines and installation) - monetary value & $\mathrm{X}$ & & Regional Civil Protection (Logistics section) \\
\hline & indirect damage (e.g. disruption, systemic) & $\mathrm{X}$ & & Regional Civil Protection (Emergency Management Centre) \\
\hline & $\begin{array}{l}\text { indirect damage (e.g. disruption, systemic) - monetary } \\
\text { value }\end{array}$ & & $X$ & \\
\hline & mitigation actions (before and during the event) & $\mathrm{X}$ & & Regional Civil Protection (Logistics section) \\
\hline \multirow{6}{*}{$\sum_{\substack{\pi\\
}}^{\infty}$} & $\begin{array}{l}\text { location/vulnerability (e.g. classification, functional and } \\
\text { systemic vulnerability) }\end{array}$ & $\mathrm{X}$ & & Region Authority \\
\hline & direct damage (lines and installation) & $\mathrm{X}$ & & Regional Civil Protection (Emergency Management Centre) \\
\hline & direct damage (lines and installation) - monetary value & & $\mathrm{X}$ & \\
\hline & indirect damage (e.g. disruption, systemic) & $\mathrm{X}$ & & Regional Civil Protection (Emergency Management Centre) \\
\hline & $\begin{array}{l}\text { indirect damage (e.g. disruption, systemic) - monetary } \\
\text { value }\end{array}$ & & $\mathrm{X}$ & \\
\hline & mitigation actions (before and during the event) & & $\mathrm{X}$ & \\
\hline \multirow{6}{*}{ 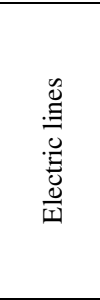 } & $\begin{array}{l}\text { location/vulnerability (e.g. classification, functional and } \\
\text { systemic vulnerability) }\end{array}$ & & $\mathrm{X}$ & \\
\hline & direct damage (lines and installation) & $\mathrm{X}$ & & utility company (ENEL) \\
\hline & direct damage (lines and installation) - monetary value & $\mathrm{X}$ & & utility company (ENEL) \\
\hline & indirect damage (e.g. disruption, systemic) & $\mathrm{X}$ & & utility company (ENEL) \\
\hline & $\begin{array}{l}\text { indirect damage (e.g. disruption, systemic) - monetary } \\
\text { value }\end{array}$ & & $\mathrm{X}$ & \\
\hline & mitigation actions (before and during the event) & $\mathrm{X}$ & & utility company (ENEL) \\
\hline \multirow{6}{*}{ 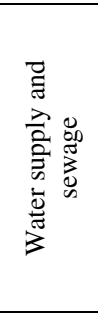 } & $\begin{array}{l}\text { location/vulnerability (e.g. classification, functional and } \\
\text { systemic vulnerability) }\end{array}$ & & $\mathrm{X}$ & \\
\hline & direct damage (lines and installation) & $\mathrm{X}$ & & utilities companies \\
\hline & direct damage (lines and installation) - monetary value & $\mathrm{X}$ & & utilities companies \\
\hline & indirect damage (e.g. disruption, systemic) & $\mathrm{X}$ & & Regional Civil Protection (Emergency Management Centre) \\
\hline & $\begin{array}{l}\text { indirect damage (e.g. disruption, systemic) - monetary } \\
\text { value }\end{array}$ & & $\mathrm{X}$ & \\
\hline & mitigation actions (before and during the event) & $\mathrm{X}$ & & utilities companies/municipalities \\
\hline \multirow{3}{*}{ 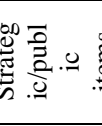 } & location/vulnerability (e.g. physical, functional, systemic) & $\mathrm{X}$ & & Region Authority \\
\hline & direct damage & $\mathrm{X}$ & & Regional Civil Protection (Logistics section) \\
\hline & direct damage - monetary value & $\mathrm{X}$ & & Regional Civil Protection (Logistics section) \\
\hline
\end{tabular}




\begin{tabular}{|c|c|c|c|c|}
\hline \multirow{5}{*}{ Sector } & \multirow{2}{*}{ Data } & \multicolumn{2}{|c|}{ Availability } & \multirow{2}{*}{ Source } \\
\hline & & Yes & No & \\
\hline & indirect damage (e.g. service disruption) & $\mathrm{X}$ & & Regional Civil Protection (Emergency Management Centre) \\
\hline & $\begin{array}{l}\text { indirect damage (e.g. disruption, systemic) - monetary } \\
\text { value }\end{array}$ & & $\mathrm{X}$ & \\
\hline & mitigation actions (before and during the event) & $\mathrm{X}$ & & municipalities \\
\hline \multirow{7}{*}{ 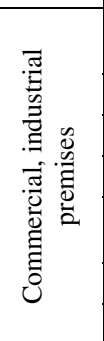 } & $\begin{array}{l}\text { location/vulnerability (e.g. physical, monetary sector, } \\
\text { personnel) }\end{array}$ & $X$ & & Region Authority \\
\hline & monetary value (e.g. net capital value) & $\mathrm{X}$ & & National statistical Office (ISTAT) \\
\hline & direct damage & $\mathrm{X}$ & & Survey, trade associations, municipalities \\
\hline & direct damage - monetary value & $\mathrm{X}$ & & trade associations, municipalities \\
\hline & $\begin{array}{l}\text { indirect damage (e.g. loss of income, clean- up) - monetary } \\
\text { value }\end{array}$ & $X$ & & Survey, trade associations, municipalities \\
\hline & indirect damage - monetary value & & $\mathrm{X}$ & \\
\hline & mitigation actions (before and during the event) & $\mathrm{X}$ & & Survey \\
\hline \multirow{7}{*}{ 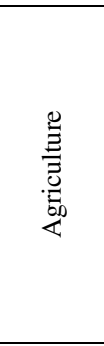 } & $\begin{array}{l}\text { location/vulnerability (e.g. physical, monetary sector, } \\
\text { personnel) }\end{array}$ & $X$ & & National cadastre \\
\hline & monetary value (e.g. net capital value) & $\mathrm{X}$ & & National statistical Office (ISTAT) \\
\hline & direct damage & & $\mathrm{X}$ & \\
\hline & direct damage - monetary value & $\mathrm{X}$ & & Regional Authority (Agricultural section) \\
\hline & $\begin{array}{l}\text { indirect damage (e.g. loss of income, clean- up) - monetary } \\
\text { value }\end{array}$ & & $\mathrm{X}$ & \\
\hline & indirect damage - monetary value & & $\mathrm{X}$ & \\
\hline & mitigation actions (before and during the event) & & $\mathrm{X}$ & \\
\hline \multirow{7}{*}{ 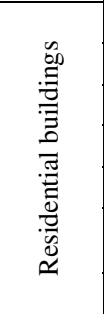 } & market value & $\mathrm{X}$ & & Real estate database /insurers \\
\hline & location/vulnerability (e.g. maintenance, typology) & $\mathrm{X}$ & & Region Authority \\
\hline & direct damage & $\mathrm{X}$ & & Survey/Municipalities \\
\hline & direct damage - monetary value & $\mathrm{X}$ & & Municipalities/Region Authority \\
\hline & indirect damage (e.g. evacuation, clean-up, etc.) & $\mathrm{X}$ & & Survey \\
\hline & $\begin{array}{l}\text { indirect damage (e.g. evacuation, clean-up, etc.) - } \\
\text { monetary value }\end{array}$ & & $\mathrm{X}$ & \\
\hline & mitigation actions (before and during the event) & $\mathrm{X}$ & & Survey \\
\hline \multirow{4}{*}{ 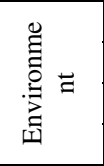 } & location/vulnerability & $\mathrm{X}$ & & Region Authority \\
\hline & direct damage & $\mathrm{X}$ & & Region Authority \\
\hline & indirect damage & $\mathrm{X}$ & & Region Authority \\
\hline & mitigation actions (before and during the event) & $\mathrm{X}$ & & Region Authority \\
\hline \multirow{4}{*}{ 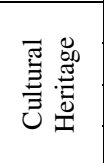 } & location/vulnerability & $\mathrm{X}$ & & Region Authority \\
\hline & direct damage & $\mathrm{X}$ & & Regional Civil Protection (Logistics section) \\
\hline & indirect damage & & $\mathrm{X}$ & \\
\hline & mitigation actions (before and during the event) & & $\mathrm{X}$ & \\
\hline \multirow{3}{*}{ 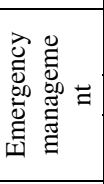 } & employed resources (sand bags, tends, vehicles, etc.) & $\mathrm{X}$ & & $\begin{array}{l}\text { Regional Civil Protection (Emergency Management } \\
\text { Centre)/municipalities }\end{array}$ \\
\hline & emergency costs & $\mathrm{X}$ & & Regional Civil Protection (Logistics section)/municipalities \\
\hline & personnel & $X$ & & $\begin{array}{l}\text { Regional Civil Protection (Emergency Management } \\
\text { Centre)/municipalities }\end{array}$ \\
\hline \multirow{5}{*}{ 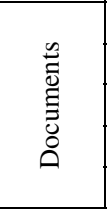 } & reports, & $\mathrm{X}$ & & Region Authority \\
\hline & ordinances, decrees, etc. & $\mathrm{X}$ & & Region Authority \\
\hline & emergency plans & $\mathrm{X}$ & & Region Authority \\
\hline & master plans & $\mathrm{X}$ & & Region Authority \\
\hline & Observation from surveys & $\mathrm{X}$ & & Region Authority \\
\hline
\end{tabular}

Table 2. Available data for the 2012 and 2013 floods in the Umbria Region 


\section{Conclusion}

This paper presents first results from the IDEA (Improving Damage assessments to Enhance cost-benefit Analyses) project. With the main aim of overcoming the very limited reliability of data currently used to support cost-benefit analyses in the field of flood risk mitigation, a comprehensive understanding of (i) how disaster data are presently collected and stored, (ii) main reasons for data collection, (iii) possible uses of collected data, and (iv) stakeholders involved in data collection and management, was performed in the project by means of the analysis of several case studies.

Results show that, at present, the availability and quality of disaster data is mainly impaired by the presence of several public and private stakeholders that own, collect and use damage data without a coordination, shared protocols and procedures. This lead to the incomparability of available data, problems in data sharing and the lack of information on key aspects for cost-benefit analysis (i.e. typically data on exposure and vulnerability of affected items).

The importance of a common platform for data sharing as well as of shared procedures for data collection (that envisages also the integration of present missing information) has then been identified as a key objective for the IDEA project.

\section{Acknowledgement}

The research described in the paper has been developed within the project "IDEA" (Improving Damage assessments to Enhance cost-benefit Analyses, EU prevention and preparedness project in civil protection and marine pollution) funded by DG-ECHO, ( G.A.N. ECHO/SUB/2014/694469).Authors acknowledge with gratitude all the people involved in the project.

\section{References}

1. Meyer V., Becker N., Markantonis V., Schwarze R., Van den Bergh J. C. J. M., Bouwer L. M., Bubeck P., Ciavola P., Genovese E., Green C., Hallegatte S., Kreibich H., Lequeux Q., Logar I., Papyrakis E., Pfurtscheller C., Poussin J., Przyluski V., Thieken A. H. and Viavattene C. (2013) Review article: Assessing the costs of natural hazards - state of the art and knowledge gaps, Nat. Hazards Earth Syst. Sci., 13, 1351-1373

2. Handmer J. (2003) The chimera of precision: inherent uncertainties in disaster loss assessment. International journal of mass emergencies and disasters, 20 (3), 325-346.

3. JonkmanS.N., Brinkhuis-Jak M. and Kok M. (2004), Cost benefit analysis and flood damage mitigation in the Netherlands, Heron, 49(1)

4. Directive 2007/60/EU of the European Parliament and of the Council of 23 October 2007 on the assessment and management of flood risks, Official Journal of the European Union, 2007
5. IDEA Project, Del. A.1 and A.2 Technical report on (i) existing practices for data collection, (ii) stakeholders and (iii) available data in the case studies, www.ideaproject.polimi.it

6. Molinari D., Menoni S., Aronica G.T., Ballio F., Berni N., Pandolfo C., Stelluti M. and Minucci G. (2013) Ex-post damage assessment: an Italian experience. Nat. Hazards Earth Syst. Sci., 14, 901916

7. Ballio F., Molinari D., Minucci G., Mazuran M., Arias Munoz C., Menoni S., Atun F., Ardagna D., Berni N and Pandolfo C. (2015) The RISPOSTA procedure for the collection, storage and analysis of high quality, consistent and reliable damage data in the aftermath of floods, Journal of Flood Risk Management, on line first 